\title{
Global transcriptome-wide analysis of the function of GDDR in acute gastric lesions
}

\author{
ZIQIANG ZHANG $^{1 *}$, JIE ZHU $^{2 *}$, YUANQIANG DONG $^{1}$, HONGYUAN XUE $^{1}$, TAO JIANG $^{1}$, WENSHUAI LI ${ }^{2}$, \\ DIANNAN XU ${ }^{2}$, LIUBIN SHI ${ }^{1}$, JIANGHONG YU ${ }^{2}$, JUN ZHANG ${ }^{2}$ and JIANJUN DU ${ }^{1}$
}

Departments of ${ }^{1}$ General Surgery and ${ }^{2}$ Digestive Diseases, Huashan Hospital, Fudan University, Shanghai 200040, P.R. China

Received December 20, 2016; Accepted July 25, 2017

DOI: $10.3892 / \mathrm{mmr} .2017 .7687$

\begin{abstract}
Acute gastric lesions induced by stress are frequent occurrences in medical establishments. The gastric dramatic downrelated gene (GDDR) is a secreted protein, which is abundantly expressed in normal gastric epithelia and is significantly decreased in gastric cancer. In our previous study, it was found that GDDR aggravated stress-induced acute gastric lesions. However, the role of GDDR in acute gastric lesions remains to be fully elucidated. In the present study, RNA sequencing was performed in order to examine the gene expression profile regulated by GDDR in acute gastric lesions. The dataset comprised four stomach samples from wild-type (WT) mice and four stomach samples from GDDR-knockout mice. Gene Ontology (GO) and Kyoto Encyclopedia of Genes and Genomes (KEGG) pathway enrichment analyses were performed to analyze the differentially-expressed genes (DEGs). Weighted correlation network analysis was used to identify clusters of highly correlated genes. Cytoscape was used to construct a protein-protein interaction network (PPI) of the DEGs. Based on the GO analysis, the upregulated DEGs were distinctly enriched in muscle contraction and response to wounding; and the downregulated DEGs were significantly enriched in the regulation of nitrogen compound metabolic process and regulation of RNA metabolic process. The results of the KEGG pathway analysis showed that the upregulated DEGs were enriched in ECM-receptor interaction and the signaling pathway of cGMP-PKG, and the downregulated
\end{abstract}

Correspondence to: Professor Jianjun Du, Department of General Surgery, Huashan Hospital, Fudan University, 12 Middle Urumqi Road, Shanghai 200040, P.R. China

E-mail: dujjp@hotmail.com

Dr Jun Zhang, Department of Digestive Diseases, Huashan Hospital, Fudan University, 12 Middle Urumqi Road, Shanghai 200040, P.R. China

E-mail: archsteed@163.com

*Contributed equally

Key words: gastric dramatic downrelated gene, acute gastric lesion, transcriptome, stress, network
DEGs were enriched in the renin-angiotensin system and glycerolipid metabolism. The co-expression network revealed a group of genes, which were associated with increased wound healing in the WT mice. Significant pathways were identified through the PPI network, including negative regulation of the signaling pathway of glucocorticoid receptor, regulation of cellular stress response, and regulation of hormone secretion. In conclusion, the present study improves current understanding of the molecular mechanism underlying acute gastric lesions and may assist in the treatment of gastric lesions.

\section{Introduction}

The disruption of homeostasis causes stress in response to damage to the body. However, sustained stress can lead to organ injury and diseases, including hypertension, diabetes, gastric ulcers and cancer. Gastric lesions are a typical organ injury associated with stress (1). A water immersion restraint stress (WRS) model, which has been widely used in investigating stress-associated organ injury, imitates the clinical acute gastric lesions resulting from surgery, trauma and sepsis (2). Elucidation of the mechanism underlying gastric injury induced by stress, and the development of specific therapeutic drugs are practically and clinically important. Physiological and psychological stress are involved in the pathogenesis of gastric ulceration. Anxiety, depression, helplessness and fear are considered to be the psychological responses (3). Neurohormonal and immunological activation are incorporated in the physiological responses, and these two systems can interact under circumstances of stress $(4,5)$. However, the mechanisms underlying stress-induced acute gastric lesions remain to be elucidated.

The novel gastric dramatic downrelated gene (GDDR), which was also known as gastrokine 2, was first cloned using the Ends-Marathon Racein method, described in our previous study (6). The expression of GDDR has been confirmed to be high in gastric mucosa epithelial cells in particular (7), however, the expression of GDDR is significantly reduced in gastric cancer (8). In the gastrointestinal tract, the secretion of GDDR is regulated by a series of cytokines, including interleukin (IL)-8 and IL-6, in addition to transforming growth factors (TGF)s (9). The loss of GDDR drives premalignant gastric inflammation and tumor progression (10). Poor prognosis and lymph node metastasis in gastric cancer have 
Table I. Statistical results of raw and mapped reads from RNA sequencing analysis of the two sample groups.

\begin{tabular}{|c|c|c|c|c|c|c|}
\hline $\begin{array}{l}\text { Sample } \\
\text { ID }\end{array}$ & $\begin{array}{l}\text { All reads } \\
\quad(\mathrm{n})\end{array}$ & $\begin{array}{l}\text { Mapped } \\
\text { reads }(n)\end{array}$ & $\begin{array}{l}\text { Mapped pair } \\
\text { reads }(n)\end{array}$ & $\begin{array}{l}\text { Mapped unique } \\
\text { reads }(n)\end{array}$ & $\begin{array}{l}\text { Mapped multi } \\
\text { reads }(n)\end{array}$ & $\begin{array}{l}\text { Mapping } \\
\text { ratio }(\%)\end{array}$ \\
\hline WT1 & $61,240,034$ & $59,117,022$ & $56,525,230$ & $55,294,584$ & $3,822,438$ & 96.53 \\
\hline WT2 & $46,121,381$ & $44,464,612$ & $42,679,266$ & $41,326,294$ & $3,138,318$ & 96.41 \\
\hline WT3 & $54,133,981$ & $52,125,800$ & $49,324,700$ & $49,085,506$ & $3,040,294$ & 96.29 \\
\hline WT4 & $54,339,065$ & $52,141,402$ & $49,743,718$ & $48,844,972$ & $3,296,430$ & 95.96 \\
\hline KO1 & $72,474,184$ & $70,219,525$ & $65,940,540$ & $63,560,829$ & $6,658,696$ & 96.89 \\
\hline $\mathrm{KO} 2$ & $82,629,329$ & $80,169,680$ & $75,009,586$ & $73,414,418$ & $6,755,262$ & 97.02 \\
\hline KO3 & $56,526,935$ & $54,505,009$ & $52,003,246$ & $50,639,935$ & $3,865,074$ & 96.42 \\
\hline KO4 & $58,853,154$ & $56,795,811$ & $54,334,810$ & $51,286,425$ & $5,509,386$ & 96.50 \\
\hline
\end{tabular}

WT, wild-type mouse; KO, gastric dramatic downrelated gene-knockout mouse.

been closely linked to the loss of GDDR (11). The expression of GDDR may suppress cancer cell proliferation through a TFF1-dependent manner, and induces apoptosis through the extrinsic apoptotic pathway $(12,13)$. Therefore, GDDR contributes to gastric mucosa homeostasis (14) and acts as a putative tumor suppressor (15). The function of GDDR remains to be fully elucidated unclear, however our previous study (16) found that GDDR aggravated stress-induced gastric lesions, however, no significant differences were found between wild-type (WT) mice and GDDR-knockout (KO) mice without stress.

As it was previously shown that the expression of GDDR in gastric cancer significantly aggravated gastric lesions, based on biological functions and pathways analysis, the present study aimed to examine the process underlying gastric lesions at the molecular level, and provide insight for the identification of potential candidate biomarkers for drug targets, diagnosis and prognosis.

\section{Materials and methods}

Formation of WRS-induced gastric mucosal lesions in mice. A total of $8 \mathrm{KO}$ mice (male; age, 6-8 weeks; weight, $20 \mathrm{~g}$ ) were purchased from the Mutant Mouse Resource Research Center (Sacramento, CA, USA). The handling and care of the animals was implemented with reference to the National Institutes of Health guidelines. The temperature within the cages was controlled at $25 \pm 3^{\circ} \mathrm{C}$, and the humidity was kept at $50 \pm 5 \%$. Mice were given free access to water and food. The present study was performed following the approval of the Animal Experimentation Ethics Committee of Fudan University (Shanghai, China). The WRS model used in the present study has been widely used in investigations of gastric lesions (17). The WRS model can mimic acute gastric lesions in humans to a high degree. GDDR shows stomach-restricted expression and is highly conserved among mammals (18); therefore, GDDR shares similar functions among mammals. Prior to each experiment, the animals were starved for $24 \mathrm{~h}$. The immersing of animals in water was performed to the extent of the xiphoid process in a restraint cage as previously described (19). Following exposure to stress for the indicated duration $(0$ to $8 \mathrm{~h}$ ), the animals were sacrificed. The stomachs of the animals were removed and immersed in RNAlater (Thermo Fisher Scientific, Inc., Waltham, MA, USA) for 1 day. By cutting along the greater curvature, the stomachs were cut open and used for RNA extraction.

RNA extraction and quality control. TRIzol ${ }^{\circledR}$ reagent (Thermo Fisher Scientific, Inc.) was used to extract total RNA from each sample, according to the manufacturer's protocol. The concentrations of all samples were determined using a NanoDrop ND-2000 spectrophotometer (Thermo Fisher Scientific, Inc.). The Agilent Bioanalyzer 2100 (Agilent Technologies, Inc., Santa Clara, CA, USA) was used to evaluate the quality.

Preparation of whole transcriptome libraries and deep sequencing. The Ion Total RNA-Seq kit v2 (Thermo Fisher Scientific, Inc.) was used to construct the sequencing library of the RNA samples in accordance with the manufacturer's protocol (Thermo Fisher Scientific, Inc.). In brief, Dynabeads mRNA purification (Thermo Fisher Scientific, Inc.) was utilized for refining poly(A)-containing mRNA. Fragmentation of the mRNA was implemented with the use of RNaseIII, following which the mRNA was purified. Subsequently, reverse transcription of the RNA fragments was performed by SuperScript ${ }^{\mathrm{TM}}$ II Reverse Transcriptase (Thermo Fisher Scientific, Inc.). The reverse transcribed mRNA was then amplified into double-stranded cDNA $\left(42^{\circ} \mathrm{C}, 50 \mathrm{~min} ; 70^{\circ} \mathrm{C}\right.$, $15 \mathrm{~min}$ ), and was purified using a magnetic bead-based approach, following which concentrations of the samples were detected for the cDNA library. Sequencing quality was analyzed by RSeQC (version 2.6; http://rseqc.sourceforge. net/).

Raw read filtering and mapping. The filtered raw reads $\geq 50$ bp were used for the mapping. The TopHat (version 2.0.9; http://ccb.jhu.edu/software/tophat/index.shtml) tool was used for the RNA sequencing (RNA-seq) data mapping analysis based on spliced mapping, which is able to immediately and accurately identify the eukaryotic splicing (20). EdgeR (version 3.5; http://www.bioconductor.org/packages/release/bioc/html/edgeR.html) was used to identified the differentially-expressed genes (DEGs). 


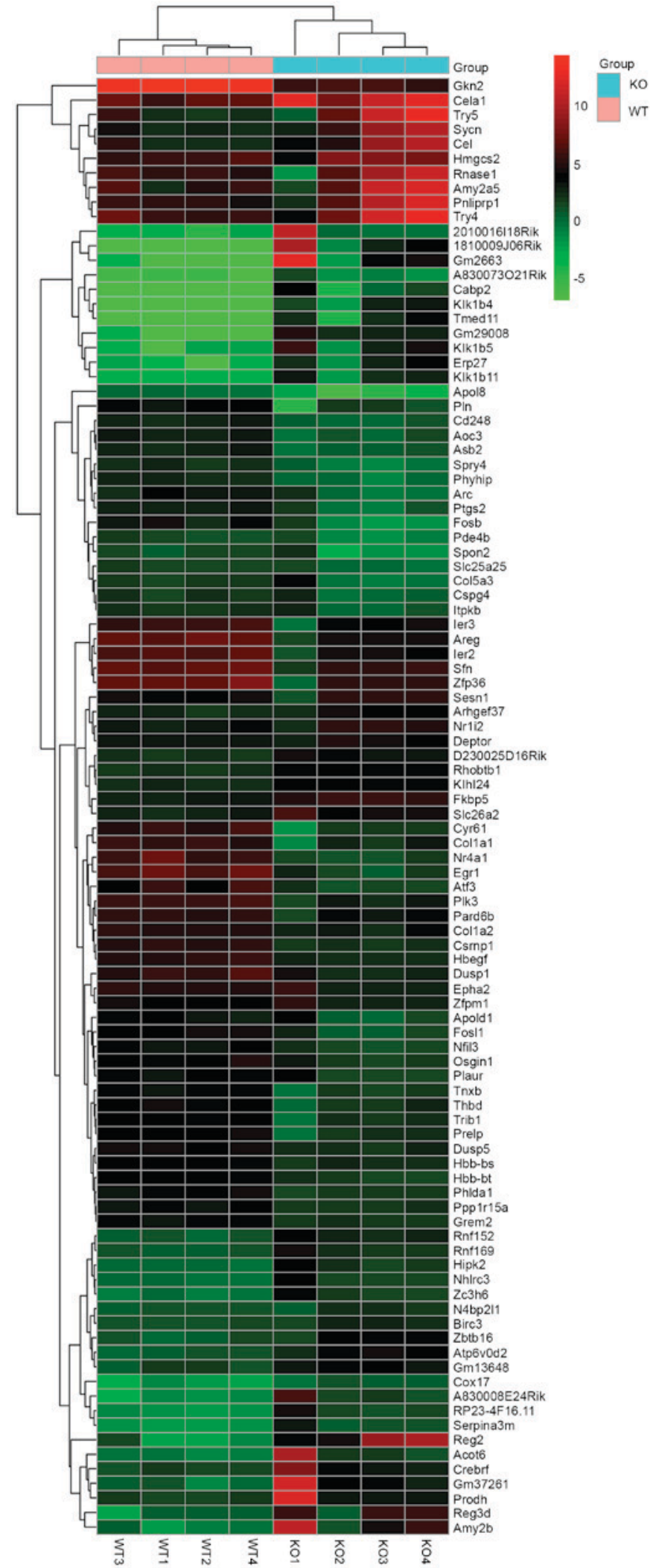

Figure 1. Heat map of the top 100 differentially-expressed genes. The heat map shows the 50 upregulated genes and 50 downregulated genes. Red indicates upregulation; green indicates downregulation. WT, wild-type; KO, knockout.

Gene Ontology (GO) and pathway enrichment analysis of DEGs. For the functional analysis of the DEGs, GO analysis was used to annotate genes and gene products, and to identify characteristic biological properties for high-throughput transcriptome or genome data (21). Kyoto Encyclopedia of Genes and Genomes pathway (KEGG; http://www.genome.jp/) was used for systematic genetic functional analysis, to connect higher-order functional information with genomic information (22). The genes were mapped to the relevant biological annotation in the Database for Annotation, Visualization and Integrated Discovery (DAVID; https://david.ncifcrf.gov/) to perform high-throughput gene functional analysis (23). $\mathrm{P}<0.05$ was considered to indicate a statistically significant difference.

Co-expression network. For each gene pair, the Pearson correlation coefficient was calculated and important correlation pairs were selected in order to establish the network (24). The degree of centrality of a gene in the network was measured to determine the relative significance. By definition, the degree of centrality is the number of links of one node relative to another (25).

Integrative analysis of protein-protein interaction (PPI) networks and modules. The Search Tool for the Retrieval of Interactive Genes (STRING) database is an online tool for evaluating PPI information. The STRING database (version 10.0; https://string-db.org/) contains 9,600,000 types of protein in 2,000 organisms. For the assessment of interactions among DEGs in the present study, the DEGs were uploaded to the STRING database, and only interactions with a composite score $>0.4$, which were experimentally validated, were considered to be significant. Cytoscape software (version 3.5.1; www. cytoscape.org) was then used to construct the PPI networks. Plug-in Molecular Complex Detection (MCODE) was then utilized for screening the PPI network modules in Cytoscape. The outcomes of the pathway and functional enrichment analysis were used for analyzing DEGs in the modules.

Reverse-transcription-quantitative polymerase chain reaction (RT-qPCR) analysis. The RT-qPCR assay was performed on the CFX96 Touch $^{\mathrm{TM}}$ (Bio-Rad Laboratories, Inc., Hercules, CA, USA). According to the manufacturer's protocol, TRIzol ${ }^{\circledR}$ reagent (Thermo Fisher Scientific, Inc.) was used to extract RNA from each sample. According to the manufacturer's protocol, cDNA synthesis was performed from $1 \mu \mathrm{g}$ RNA with the use of a FastQuant RT kit (Tiangen Biotech Co., Ltd., Beijing, China). Subsequently, the PCR mixtures $(25 \mu \mathrm{l})$ were prepared in triplicate, each containing 12.5 $\mu 1 \mathrm{SYBR}{ }^{\circledR}$ Premix Ex Taq (Takara Bio, Inc., Otsu, Japan), $1 \mu \mathrm{l}$ of cDNA template, $0.5 \mu \mathrm{l}$ primer $(10 \mathrm{mM}$; Genewiz, Inc., Suzhou, China) and $3.6 \mathrm{ml}$ DEPC-treated water. The primers included the following: Chemokine (C-X-C motif) ligand $2(\mathrm{Cxcl} 2)$ forward, 5'-CCAACCACCAGGCTACAG G-3' and reverse, 5'-GCGTCACACTCAAGCTCTG-3'; Tgf- $\beta 1$ forward, 5'-CTCCCGTGGCTTCTAGTGC-3' and reverse, 5'-GCCTTAGTTTGGACAGGATCTG-3'; IL-1 $\beta$ forward, 5'GCAACTGTTCCTGAACTCAACT-3' and reverse, 5'-ATC TTTTGGGGTCCGTCAACT-3'; insulin II (Ins2) forward, 5'-GCTTCTTCTACACACCCATGTC-3' and reverse, 5'-AGC ACTGATCTACAATGCCAC-3'; serine/threonine kinase 2 (Sgk2) forward, 5'-CCATTGGTTACCTTCACTCTCTC-3' and reverse, 5'-GTCTCCTCAGGCTCTACACAT-3'; tuberous sclerosis 1 (Tsc1) forward, 5'-ACTCTCCCTTCTACCGAG ACA-3' and reverse, 5'-GAGGCTGCCGAATGAGTCTTC-3'; 
Table II. Differentially-expressed genes associated with functions and phenotypes.

\begin{tabular}{|c|c|c|c|c|}
\hline Gene symbol & Description & $\log 2 \mathrm{FC}$ & P-value & Gene ontology term \\
\hline \multicolumn{5}{|l|}{ Upregulated } \\
\hline Hbegf & $\begin{array}{l}\text { Heparin binding EGF-like } \\
\text { growth factor }\end{array}$ & -2.86 & $3.79 \times 10^{-34}$ & $\begin{array}{l}\text { Angiogenesis; extracellular space; epidermal } \\
\text { growth factor receptor signaling pathway; growth } \\
\text { factor activity }\end{array}$ \\
\hline Ptgs2 & $\begin{array}{l}\text { Prostaglandin-endoperoxide } \\
\text { synthase } 2\end{array}$ & -1.88 & $2.83 \times 10^{-09}$ & $\begin{array}{l}\text { Negative regulation of toll-like receptor signaling } \\
\text { pathway; prostaglandin biosynthetic process; }\end{array}$ \\
\hline $\mathrm{Cxcl} 2$ & $\begin{array}{l}\mathrm{C}-\mathrm{X}-\mathrm{C} \text { motif chemokine } \\
\text { ligand } 2\end{array}$ & -3.97 & $3.80 \times 10^{-07}$ & $\begin{array}{l}\text { Cytokine activity; extracellular region; } \\
\text { inflammatory response; G-protein coupled } \\
\text { receptor signaling pathway; neutrophil chemotaxis }\end{array}$ \\
\hline Tgf- $\beta 1$ & $\begin{array}{l}\text { Transforming growth } \\
\text { factor- } \beta 1\end{array}$ & -1.48 & $1.55 \times 10^{-06}$ & $\begin{array}{l}\text { Transcription coactivator activity; focal adhesion; } \\
\text { positive regulation of epithelial to mesenchymal } \\
\text { transition; Wnt signaling pathway }\end{array}$ \\
\hline IL-1 $\beta$ & Interleukin-1 $\beta$ & -2.58 & $2.28 \times 10^{-04}$ & $\begin{array}{l}\text { Activation of MAPK activity; positive regulation } \\
\text { of protein phosphorylation cytokine activity }\end{array}$ \\
\hline \multicolumn{5}{|l|}{ Downregulated } \\
\hline Ins2 & Insulin II & 5.01 & $7.42 \times 10^{-11}$ & $\begin{array}{l}\text { Negative regulation of transcription from RNA } \\
\text { polymerase II promoter; MAPK cascade; nega- } \\
\text { tive regulation of acute inflammatory response; } \\
\text { extracellular region }\end{array}$ \\
\hline Tsc 1 & Tuberous sclerosis 1 & 1.31 & $4.44 \times 10^{-09}$ & $\begin{array}{l}\text { Regulation of cell-matrix adhesion; adaptive } \\
\text { immune response; protein binding; cytoplasm }\end{array}$ \\
\hline Sgk2 & Serine/threonine kinase 2 & 1.22 & $1.06 \times 10^{-08}$ & $\begin{array}{l}\text { Nucleotide binding; regulation of cell growth; } \\
\text { protein serine/threonine kinase activity; cytoplasm }\end{array}$ \\
\hline Erbb3 & $\begin{array}{l}\text { Erb-B2 receptor tyrosine } \\
\text { kinase } 3\end{array}$ & 1.07 & $3.75 \times 10^{-07}$ & $\begin{array}{l}\text { Nucleotide binding; protein kinase activity; } \\
\text { transmembrane receptor protein tyrosine kinase } \\
\text { activity; receptor signaling protein tyrosine kinase } \\
\text { activity; protein binding }\end{array}$ \\
\hline Adgrb1 & $\begin{array}{l}\text { Adhesion } \mathrm{G} \text { protein-coupled } \\
\text { receptor B } 1\end{array}$ & 1.17 & $1.24 \times 10^{-06}$ & $\begin{array}{l}\text { Transmembrane signaling receptor activity; } \\
\text { G-protein coupled receptor activity; protein } \\
\text { binding; plasma membrane }\end{array}$ \\
\hline
\end{tabular}

FC, fold change; MAPK, mitogen-activated protein kinase.

erb-B2 receptor tyrosine kinase 3 (Erbb3) forward, 5'-AAG TGACAGGCTATGTACTGGT-3' and reverse, 5'-GCTGGA GTTGGTATTGTAGTTCA-3'; heparin-binding epidermal grow th factor-like growth factor (Hbegf) forward, 5'-CGG GGAGTGCAGATACCTG-3' and reverse, 5'-TTCTCCACT GGTAGAGTCAGC-3'; prostaglandin-endoperoxide synthase 2 (Ptgs2) forward, 5'-TTCAACACACTCTATCACTGGC-3' and reverse, 5'-AGAAGCGTTTGCGGTACTCAT-3'; adhesion G protein-coupled receptor B1 (Adgrb1) forward, 5'-TTGCTC CACTCCTGCTGTTAC-3' and reverse, 5'-GTAGCCGAA GAACTTTCCCTG-3'; glyceraldehyde 3-phosphate dehydrogenase (GAPDH) forward, 5'-TGGATTTGGACGCATTGG TC-3' and reverse, 5'-TTTGCACTGGTACGTGTTGAT-3'. The conditions included initial denaturation at a temperature of $95^{\circ} \mathrm{C}$ for $30 \mathrm{sec}$, followed by 40 cycles $\left(95^{\circ} \mathrm{C}, 5 \mathrm{sec} ; 60^{\circ} \mathrm{C}, 30 \mathrm{sec}\right)$. Finally all quantified values were normalized to the endogenous GAPDH control. The $2^{-\Delta \Delta \mathrm{Cq}}$ method was used to analyze gene expression levels (26).

Statistical analysis. The statistical analyses of data were performed using Student's t-test with SPSS software version 17.0 (SPSS, Inc., Chicago, IL, USA). Data are presented as the mean \pm standard deviation. $\mathrm{P}<0.05$ was considered to indicate a statistically significant difference.

\section{Results}

Overview of sequencing data from RNA-seq analyses. The overall raw reads of the eight samples fell in the range of 46,000,000-82,000,000. Through strict quality checks, $>95 \%$ of the reads had a quality score of $\geq Q 20$. The RSeQC package was used to analyze the sequencing quality (27). The raw sequence data of each sample produced $\sim 6 \mathrm{~GB}$ of data. Of the total raw reads, $96.5 \%\left(\sim 5.87 \pm 2.15 \times 10^{7}\right.$ reads $)$ were mapped onto the mouse genome sequence in the eight separate samples (Table I) and $89.1 \%$ of the total raw reads $\left(5.42 \pm 1.92 \times 10^{7}\right.$ reads) were uniquely aligned to the mouse genome. The RNA-seq data was normalized to RPKM values for quantifying transcript expression levels.

Selection of DEGs. The total samples analyzed in the present study comprised four WT stomach samples and four $\mathrm{KO}$ 
Table III. GO analysis of differentially-expressed genes associated with gastric lesions.

\begin{tabular}{|c|c|c|c|c|c|}
\hline Expression & Category & Term/gene function & Gene count & $\%$ & P-value \\
\hline \multirow[t]{15}{*}{ Upregulated } & $\mathrm{BP}$ & GO:0006936-muscle contraction & 69 & 7.2 & $3.1 \times 10^{-32}$ \\
\hline & $\mathrm{BP}$ & GO:0007155-cell adhesion & 144 & 14.9 & $1.9 \times 10^{-16}$ \\
\hline & BP & GO:0040011-locomotion & 138 & 14.3 & $1.5 \times 10^{-15}$ \\
\hline & $\mathrm{BP}$ & GO:0009611-response to wounding & 69 & 7.2 & $3.7 \times 10^{-15}$ \\
\hline & $\mathrm{BP}$ & GO:0030198-extracellular matrix organization & 42 & 4.4 & $1.5 \times 10^{-14}$ \\
\hline & $\mathrm{CC}$ & GO:0043292-contractile fiber & 72 & 7.5 & $1.7 \times 10^{-36}$ \\
\hline & $\mathrm{CC}$ & GO:0030016-myofibril & 70 & 7.3 & $5.3 \times 10^{-36}$ \\
\hline & $\mathrm{CC}$ & GO:0044449-contractile fiber part & 67 & 7.0 & $1.1 \times 10^{-34}$ \\
\hline & $\mathrm{CC}$ & GO:0030017-sarcomere & 65 & 6.7 & $2.3 \times 10^{-34}$ \\
\hline & $\mathrm{CC}$ & GO:0005578-proteinaceous extracellular matrix & 78 & 8.1 & $2.5 \times 10^{-27}$ \\
\hline & $\mathrm{MF}$ & GO:0008092-cytoskeletal protein binding & 87 & 9.0 & $1.9 \times 10^{-12}$ \\
\hline & MF & $\begin{array}{l}\text { GO:0000982-transcription factor activity, } \\
\text { RNA polymerase II core promoter region } \\
\text { sequence-specific binding }\end{array}$ & 53 & 5.5 & $6.1 \times 10^{-12}$ \\
\hline & $\mathrm{MF}$ & GO:0005509-calcium ion binding & 76 & 7.9 & $6.9 \times 10^{-12}$ \\
\hline & $\mathrm{MF}$ & $\begin{array}{l}\text { GO:0000981-RNA polymerase II transcription } \\
\text { factor activity, sequence-specific DNA binding }\end{array}$ & 74 & 7.7 & $1.6 \times 10^{-11}$ \\
\hline & $\mathrm{MF}$ & GO:0003779-actin binding & 50 & 5.2 & $1.0 \times 10^{-10}$ \\
\hline \multirow[t]{15}{*}{ Downregulated } & $\mathrm{BP}$ & GO:0051252-regulation of RNA metabolic process & 105 & 18.5 & $3.1 \times 10^{-06}$ \\
\hline & $\mathrm{BP}$ & $\begin{array}{l}\text { GO:0051171-regulation of nitrogen } \\
\text { compound metabolic process }\end{array}$ & 115 & 20.3 & $2.9 \times 10^{-05}$ \\
\hline & $\mathrm{BP}$ & GO:0010468-regulation of gene expression & 115 & 20.3 & $4.8 \times 10^{-05}$ \\
\hline & BP & GO:0044242-cellular lipid catabolic process & 12 & 2.5 & $8.5 \times 10^{-04}$ \\
\hline & $\mathrm{BP}$ & GO:0043434-response to peptide hormone & 17 & 2.6 & $1.5 \times 10^{-02}$ \\
\hline & $\mathrm{CC}$ & GO:0005615-extracellular space & 62 & 10.9 & $1.5 \times 10^{-08}$ \\
\hline & $\mathrm{CC}$ & GO:0042588-zymogen granule & 5 & 0.9 & $1.0 \times 10^{-03}$ \\
\hline & $\mathrm{CC}$ & GO:0044421-extracellular region part & 96 & 16.9 & $1.2 \times 10^{-03}$ \\
\hline & $\mathrm{CC}$ & GO:0005576-extracellular region & 107 & 18.9 & $1.3 \times 10^{-03}$ \\
\hline & $\mathrm{CC}$ & GO:0005576-zymogen granule membrane & 4 & 0.7 & $2.3 \times 10^{-03}$ \\
\hline & MF & GO:0004252-serine-type endopeptidase activity & 29 & 5.1 & $1.6 \times 10^{-15}$ \\
\hline & MF & GO:0008236-serine-type peptidase activity & 29 & 5.1 & $2.2 \times 10^{-14}$ \\
\hline & MF & GO:0017171-serine hydrolase activity & 29 & 5.1 & $3.0 \times 10^{-14}$ \\
\hline & MF & GO:0043169-cation binding & 139 & 24.5 & $4.4 \times 10^{-12}$ \\
\hline & MF & GO:0046872-metal ion binding & 138 & 24.5 & $4.6 \times 10^{-12}$ \\
\hline
\end{tabular}

GO, Gene Ontology; BP, biological process; CC, cellular component; MF, molecular function.

stomach samples. The data were analyzed individually with the use of edgeR and the lists of DEGs were identified. According to the results of the analyses, using the criteria of fold control $>2.0$ and $\mathrm{P}<0.05$, a total of 1,704 genes were identified, of which 710 were downregulated and 994 were upregulated, respectively. The DEG gene expression heatmap is shown in Fig. 1, comprising the top 50 downregulated and upregulated genes. For targeting the DEGs, the DEGs were screened by GO terms, which were associated with phenotype (Table II).

GO term enrichment analysis. In order to identify the overrepresented categories (GO and KEGG pathways), all DEGs were uploaded to the online DAVID software. Based on the results of the $\mathrm{GO}$ analysis, there was significant enrichment of upregulated DEGs in biological processes (BP) encompassing muscle contraction, cell adhesion, and locomotion and response to wounding (Table III); there was significant enrichment of the downregulated DEGs in BPs encompassing regulation of nitrogen compound metabolic process, regulation of RNA metabolic process, and response to peptide hormone (Table III). For molecular function (MF), there was enrichment of the upregulated DEGs in transcription factor activity, cytoskeletal protein binding, sequence-specific binding by RNA polymerase II core promoter region, and calcium ion binding, and there was enrichment of the downregulated DEGs in serine-type peptidase activity, and serine-type endopeptidase activity, and serine hydrolase activity (Table III). In addition, based on the GO cell component (CC) analysis, there was significant enrichment 
Table IV. Kyoto Encyclopedia of Genes and Genomes pathway analysis of differentially-expressed genes associated with gastric lesions

\begin{tabular}{|c|c|c|c|c|c|}
\hline Pathway ID & Name & Gene count & $\%$ & P-value & Genes \\
\hline \multicolumn{6}{|l|}{ Upregulated } \\
\hline mmu04512 & $\begin{array}{l}\text { ECM-receptor } \\
\text { interaction }\end{array}$ & 22 & 2.3 & $1.6 \times 10^{-10}$ & $\begin{array}{l}\text { Col1a1, Col1a2, Col3a1, Col4a, } \\
\text { Col4a2, Col4a, Col4a6, Col5a1, } \\
\text { Col5a2, Col5a3, Col6a1, Col6a, } \\
\text { Col6a3, Fn1, Itga11, Itga3, Lamb2, } \\
\text { Npnt, Hspg2, Tnxb, Thbs1, Thbs4 }\end{array}$ \\
\hline $\mathrm{mmu} 04510$ & Focal adhesion & 32 & 3.3 & $2.1 \times 10^{-09}$ & $\begin{array}{l}\text { Shc2, Actn2, Actn3, Col1a1, Col1a2, } \\
\text { Col3a1, Col4a1, Col4a2, Col4a5, } \\
\text { Col4a6, Col5a1, Col5a2, Col5a, } \\
\text { Col6a1, Col6a2, Col6a3, Fn1, Flnc, } \\
\text { Itga11, Itga3, Jun, Lamb2, Mylk3, } \\
\text { Mylk4, Mylpf, Mylk2, Mylk, Tnxb, } \\
\text { Thbs1, Thbs4, Vegfc, Zyx }\end{array}$ \\
\hline mmu04022 & $\begin{array}{l}\text { Cgmp-PKG } \\
\text { signaling pathway }\end{array}$ & 23 & 2.5 & $6.7 \times 10^{-06}$ & $\begin{array}{l}\text { Atp2a1, Atp1a2, Atp1b2, Atf6b, } \\
\text { Adcy1, Adcy3, Adcy7, Adra1a, } \\
\text { Cacna1s, Gucy1b3, Irs2, MEF2C, } \\
\text { Mylk3, Mylk4, Mylk2, Mylk, Nfatc4, } \\
\text { Pde5a, Pln, Kcnmb1, Srf, Slc8a2, } \\
\text { Tprc6 }\end{array}$ \\
\hline mmu05146 & $\begin{array}{l}\text { PI3K-Akt } \\
\text { signaling pathway }\end{array}$ & 34 & 3.5 & $3.7 \times 10^{-05}$ & $\begin{array}{l}\text { Epha2, Atf6b, Chrm2, Col1a1, Col1a2, } \\
\text { Col3a1, Col4a1, Col4a2, Col4a5, } \\
\text { Col4a6, Col5a1, Col5a2, Col5a3, } \\
\text { Col6a1, Col6a2, Col6a3, Efna3, } \\
\text { Fgf10, Fgf11, Fgf1, Fn1, Gnb4, } \\
\text { Itga11, Itga3Lamb2, Ngfr, Ngf, Osm, } \\
\text { Nr4a, Ppp2r5b, Tnxb, Thbs1, Thbs4, } \\
\text { Vegfc }\end{array}$ \\
\hline mmu05414 & $\begin{array}{l}\text { Gastric acid } \\
\text { secretion }\end{array}$ & 12 & 1.2 & $3.2 \times 10^{-04}$ & $\begin{array}{l}\text { Atp1a2, Atp1b2, Adcy1, Adcy3, } \\
\text { Adcy7, Camk2a, Gast, Mylk3, } \\
\text { Mylk4, Mylk2, Myl, Kcne2 }\end{array}$ \\
\hline \multicolumn{6}{|l|}{ Downregulated } \\
\hline mmu04614 & $\begin{array}{l}\text { Renin-angiotensin } \\
\text { system }\end{array}$ & 8 & 1.4 & $1.7 \times 10^{-06}$ & $\begin{array}{l}\text { Mas1, Klk1, Klk1b11, Klk1b24, } \\
\text { Klk1b, Klk1b5, Klk1b8, Klk1b26 }\end{array}$ \\
\hline mmu04961 & $\begin{array}{l}\text { Endocrine and other } \\
\text { factor-regulated } \\
\text { calcium reabsorption }\end{array}$ & 7 & 1.2 & $2.5 \times 10^{-04}$ & $\begin{array}{l}\text { Klk1, Klk1b11, Klk1b24, Klk1b3, } \\
\text { Klk1b5, Klk1b8, Klk1b26 }\end{array}$ \\
\hline $\mathrm{mmu} 00561$ & Glycerolipid metabolism & 6 & 1.3 & $2.9 \times 10^{-03}$ & $\begin{array}{l}\text { Cel, Lpin1, Lpin2, Phliprp1, Pnli, } \\
\text { Pnliprp2 }\end{array}$ \\
\hline mmu03320 & PPAR signaling pathway & 5 & 1.0 & $4.7 \times 10^{-02}$ & $\begin{array}{l}\text { Acox } 2 \text {, Angpt14, Cpt1a, Cyp4a32, } \\
\text { Ehhdh }\end{array}$ \\
\hline mmu04080 & $\begin{array}{l}\text { Neuroactive ligand- } \\
\text { receptor interaction }\end{array}$ & 10 & 2.1 & $5.3 \times 10^{-02}$ & $\begin{array}{l}\text { Gpr156, Mas, 1810009j06Rik, } \\
\text { 2210010c04Rik, Oprd1, Try5, } \\
\text { Gm10334, Prss2, Sctr, Try4 }\end{array}$ \\
\hline
\end{tabular}

of the upregulated DEGs in contractile fiber, myofibril, and contractile fiber part, and also significant enrichment of downregulated DEGs in extracellular space, zymogen granule and extracellular region part (Table III).

KEGG pathway analysis. Based on the results of the KEGG pathway analysis, the most significantly enriched pathways of the downregulated DEGs and the upregulated DEGs were identified, as listed in Table IV. There was significant enrichment of the upregulated DEGs in the cGMP-PKG signaling pathway, focal adhesion, ECM-receptor interaction, PI3K-Akt signaling pathway and gastric acid secretion. There was enrichment of the downregulated DEGs in the endocrine, renin-angiotensin system, and other factor-regulated calcium reabsorption, PPAR signaling pathway, glycerolipid metabolism, and neuroactive ligand-receptor interaction. 
A

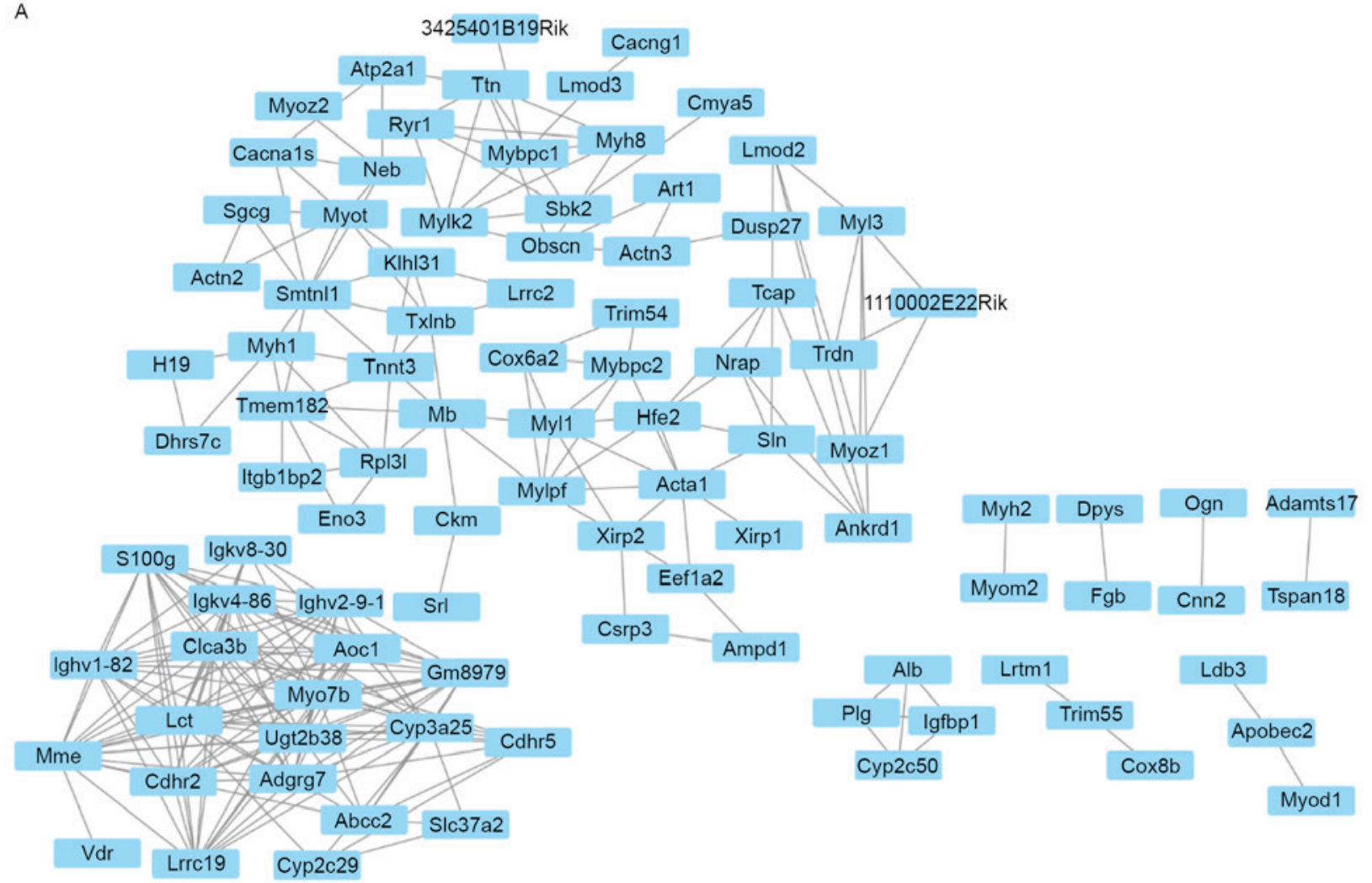

B

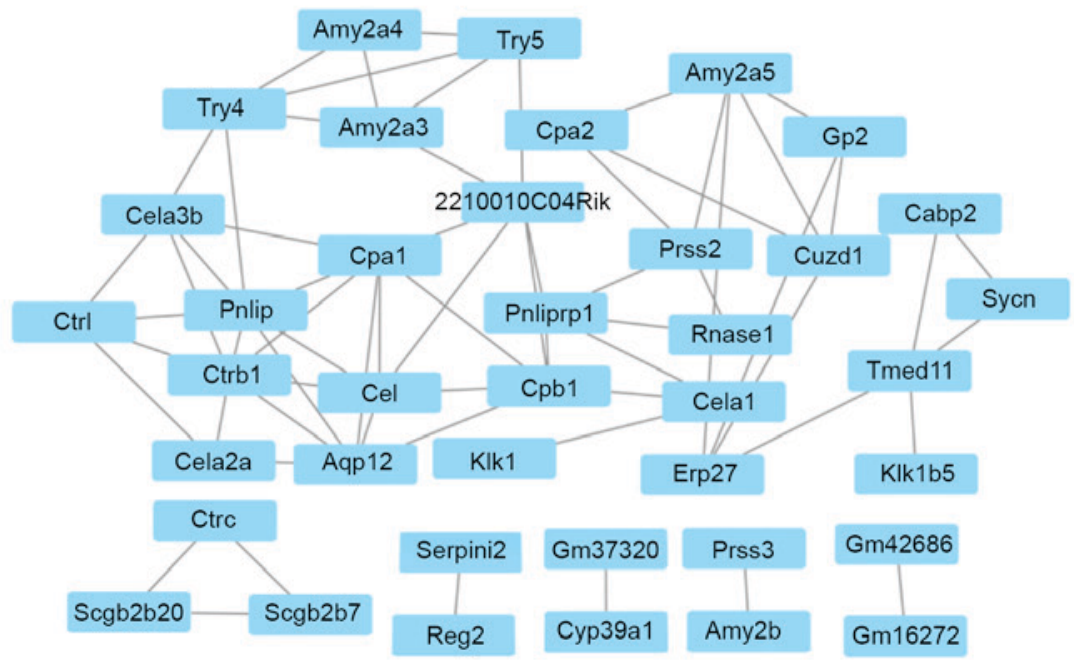

Figure 2. Gene co-expression network analysis. (A) Wild-type mice; (B) Knockout mice. Pearson's correlation coefficients of each pair of genes were calculated from these four independent samples in each group. Co-expressed genes are indicated by connecting lines.

Gene co-expression network. Gene co-expression network analysis was performed between the highlighted groups of DEGs in synergy with possible involvement in BPs resulting in phenotypic changes. As shown in Fig. 2A, there was a positive correlation between the expression levels of insulin-like growth factor-binding protein 1 and plasminogen (Pearsons $r=0.99$ ), and these genes were involved in wound healing (Fig. 2A). In addition, a family of genes were associated with wound healing, including calponin 2 , enolase 3, fibrinogen $\beta$ chain, myogenic differentiation 1 and myosin heavy chain 2 (Myh2), in the WT mice (Fig. 2A). A group of genes associated with tight junction and focal adhesion, including actinin $\alpha 2$, actinin $\alpha 3$, myosin light chain, phosphorylatable, fast skeletal muscle and Myh2, were also correlated in the WT group. In the GDDR-/-group, it was found that 12 gene pairs of genes with similar expression profiles had involvement with proteolysis, which included CUB and zona pellucida-like domains 1/carboxypeptidase A2 (Cpa2), 2210010c04Rik/carboxypeptidase B1 (Cpb1), 2210010c04Rik/trypsin 5 (Try5), Cpa1/2210010c04Rik, Cpa2/protease, serine, 2 (Prss2), Cpb1/chymotrypsin-like elastase family member 1 (Cela1), Cela1/kallikrein 1 (Klk1), Cela2a/chymotrypsin-like (Ctrl), Try4/Cela3a, Ctrb1/Ctrl and Try4/Try5 (Fig. 2B). 
A

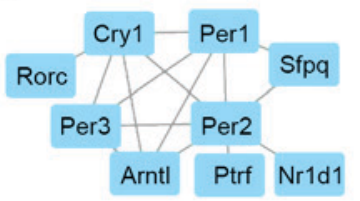

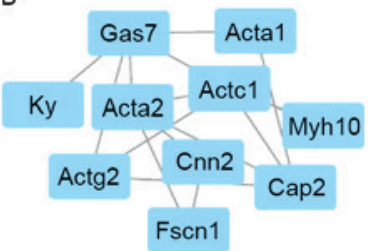

C

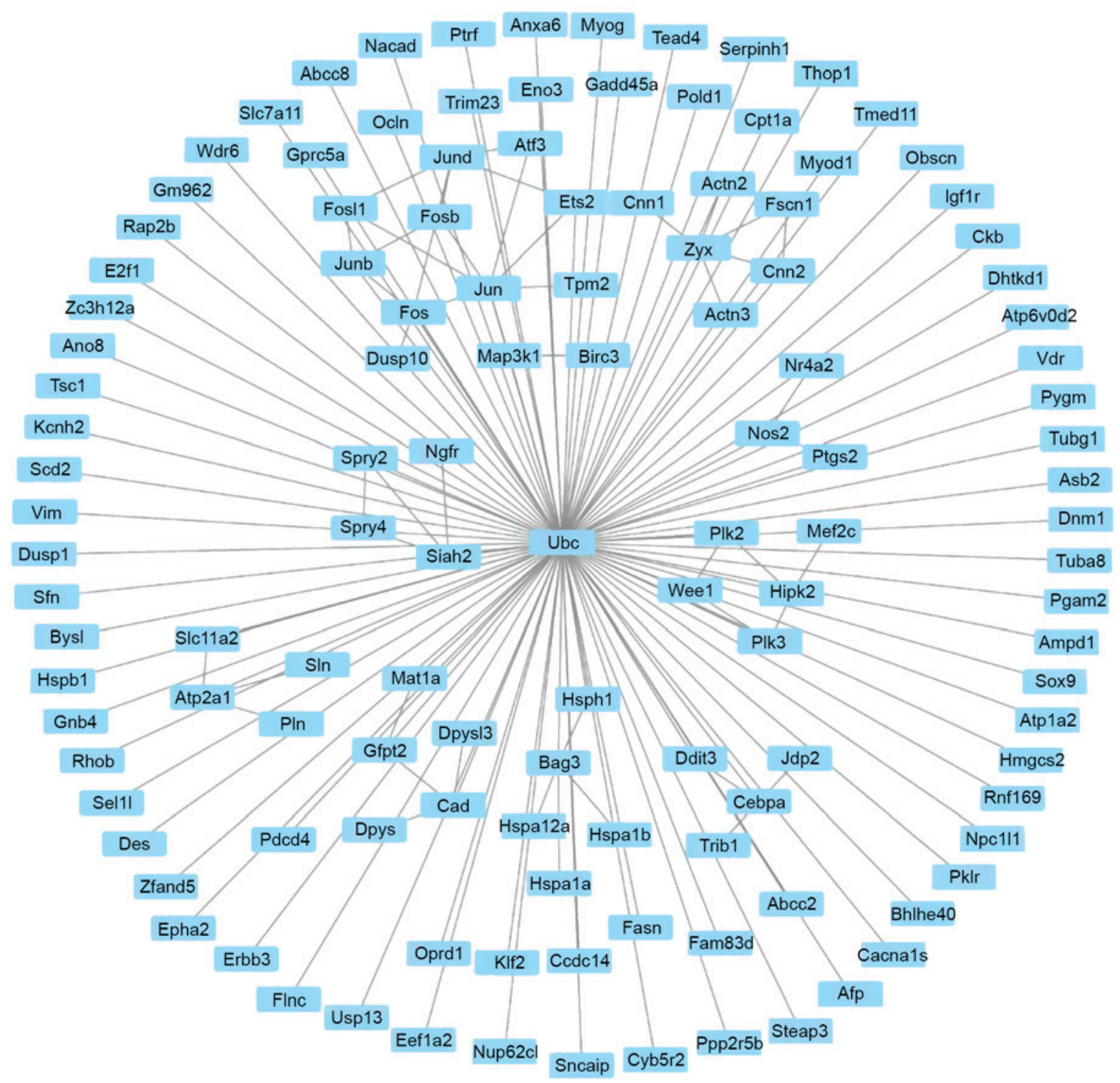

Figure 3. Top three modules from the protein-protein interaction network. (A) module 1, (B) module 2, (C) module 3. Proteins that interact directly are indicated by connecting lines.

Module screening from the PPI network. According to the STRING database results, the screening of top hub nodes with high degrees higher linked to phenotype was implemented. These encompassed period circadian clock 3 (Per3), period circadian clock 2 (Per2), Ptgs2, period circadian clock 3 (Per1), cryptochrome circadian clock 1 (Cry1), $\alpha$-actin-3 (Actg2), cardiac muscle 1 (Actc1), nitric oxide synthase 2 (Nos2), mitogen-activated protein kinase kinase kinase 1 (Map3k1), and growth arrest specific 7 (Gas7). In addition, 317 edges and 282 nodes were analyzed with the use of MCODE plug-ins. In this process, the top three significant modules were selected, and the functional genetic annotation of these modules was analyzed (Fig. 3). Based on the enrichment analysis, the genes in the top three modules were highly associated with negative regulation of the signaling pathway of glucocorticoid receptor, mesenchyme migration and response to organic substance (Table V).

Gene validation via $R T-q P C R$. The gene expression profiles of the DEGs were examined (Table II). Based on the results of the RT-qPCR analysis, the gene expression profiles of the DEGs in the two groups of samples were consistent with the RNA-seq data, with the exception of Adgrb (Fig. 4). Of note, the expression level of Ptgs 2 in the WT group was $~ 5$-fold of 
Table V. Pathways enriched in modules of the protein-protein interaction network.

\begin{tabular}{|c|c|c|c|}
\hline Gene set & P-value & FDR & Nodes \\
\hline \multicolumn{4}{|l|}{ Module 1} \\
\hline $\begin{array}{l}\text { Negative regulation of } \\
\text { glucocorticoid receptor } \\
\text { signaling pathway }\end{array}$ & $1.79 \times 10^{-07}$ & $9.81 \times 10^{-07}$ & Per1, Cry1, Arntl \\
\hline Regulation of hormone secretion & $4.21 \times 10^{-03}$ & $2.01 \times 10^{-04}$ & Per2, Nr1d1, Cry1, Arntl \\
\hline $\begin{array}{l}\text { Regulation of cellular } \\
\text { response to stress }\end{array}$ & $3.48 \times 10^{-03}$ & $7.03 \times 10^{-03}$ & Sfpq, Per1, Cry1, Arntl \\
\hline \multicolumn{4}{|l|}{ Module 2} \\
\hline Mesenchyme migration & $1.23 \times 10^{-08}$ & $1.30 \times 10^{-09}$ & Acta1, Actc1, Acta2, Actg2 \\
\hline Mesenchyme morphogenesis & $5.54 \times 10^{-05}$ & $6.76 \times 10^{-06}$ & Acta1, Actc1, Acta2, Actg2 \\
\hline Cytoskeleton organization & $4.26 \times 10^{-04}$ & $4.64 \times 10^{-04}$ & Gas7, Cap2, Cnn2, Fscn1, Myh10, Acta1 \\
\hline \multicolumn{4}{|l|}{ Module 3} \\
\hline Response to organic substance & $1.34 \times 10^{-02}$ & $4.48 \times 10^{-10}$ & $\begin{array}{l}\text { Zyx, Pygm, Slc11a2, Nos2, Ptgs2, Slc7a11, Ampd1, Epha2, } \\
\text { Zx3h12a, Hspa1a, Hsph1, Afp, Myod1, Map3k1, Jun, Dusp1, } \\
\text { Cpt1a, Dusp10, Tsc1, Fosb, Fos1, Junb, Atf3, Ddit3, HmgcS2, } \\
\text { Hipk2, Oprd1, E2f1, Bys1, Cad, Dpys12, Abcc2, Fasn, Sel11, } \\
\text { Klf2, Trib1, Abcc2, Atp1a2, Melf2c }\end{array}$ \\
\hline Response to lipid & $5.13 \times 10^{-03}$ & $2.73 \times 10^{-09}$ & $\begin{array}{l}\text { Fosb, Fos11, Fos, Jun, Nos2, Ptgs2, Dusp1, Junb, Dusp10, } \\
\text { Hmgcc2, Jund, Cebpa, Nr4a2, Trib1, Myod1, Sox9, Atp1a2, } \\
\text { E2f1, Bys1, Cad, Mef2c, Zc3h12a, Abcc2, Cpt1a }\end{array}$ \\
\hline Regulation of cell death & $8.13 \times 10^{-03}$ & $5.26 \times 10^{-08}$ & $\begin{array}{l}\text { Nr4a2, Fos11, Ptgs2, Slc11a2, Map3k1, Birc3, Junb, Jund, Atf3, } \\
\text { Ddit3, Hspb1, Gadd45a, Erbb3, Bag3, Hsph1, Plk, Plk2, Sfn, Sox, } \\
\text { Hipk2, Mef2, Vdr, Pdc, Igf1r, Rhob, Spry2, Steap3, Siah2, Ngfr }\end{array}$ \\
\hline
\end{tabular}

FDR, false discovery rate.

that in the $\mathrm{KO}$ group. Adgrb1 in the KO mice was marginally higher than that in the WT mice $(\mathrm{P}>0.05)$. Therefore, Adgrb1 may not contribute to the protection of the gastric mucosa under stress.

\section{Discussion}

In the present study, the gene expression data of four WT mice and four $\mathrm{KO}$ mice were retrieved using the RNA-seq technique. In total, 1,704 DEGs were identified between the four KO samples and WT samples, of which 710 were downregulated and 994 were upregulated. The upregulated genes included Hbegf, Ptgs $2, \operatorname{Cxcl} 2$, Tgf- $\beta 1$ and IL-1 $\beta$. These genes are involved in the inflammatory response and immune response, and may aggravate gastric lesions. The downregulated genes included Ins2, Tsc1, Sgk2, Erbb3 and Map3k1. These genes are essential in proliferation, response to oxidative stress and negative regulation of acute inflammatory response. These genes can enhance the resistance of the gastric epithelia against damage and inhibit the acute inflammatory response. It has been reported that co-expressed genes are generally composed of a family of genes, which have similar expression profiles, and are frequently involved in parallel biological process. In the present study, a co-expression network was constructed among the DEGs from the WT mice and KO mice. The network may indicate how GDDR upregulates or downregulates
DEGs, however, the results obtained in the present study were obtained from the whole stomach, containing various types of cells, therefore differences observed in the present study cannot be repeated in a single cell line. This indicates the merit of further investigation of the differences in one type of cell in the stomach. GO and KEGG pathway analyses were also performed to further elucidated the interactions of the DEGs. Based on the GO term analysis, the upregulated DEGs were predominantly associated with muscle contraction, cell adhesion, locomotion and response to wounding, whereas the downregulated DEGs were associated with regulation of nitrogen compound metabolic process, regulation of RNA metabolic process, and response to peptide hormone. These results are consistent with the knowledge that multiple processes, including increased nitrite/nitrate concentrations, the breakdown products of nitric oxide by inducible nitric oxide synthase in the gastric mucosa (28), gene expression, response to peptide hormone $(3)$, microcirculation $(29,30)$ and the vasodilator effect (31) are involved in acute gastric lesions. The KEGG pathways enriched in upregulated DEGs included focal adhesion, ECM-receptor interaction, PI3K-Akt signaling pathway, cGMP-PKG signaling pathway and gastric acid secretion (32), The KEGG pathways enriched in the downregulated DEGs included the endocrine, renin-angiotensin system, other factor-regulated calcium reabsorption, glycerolipid metabolism, PPAR signaling pathway and neuroactive 
A
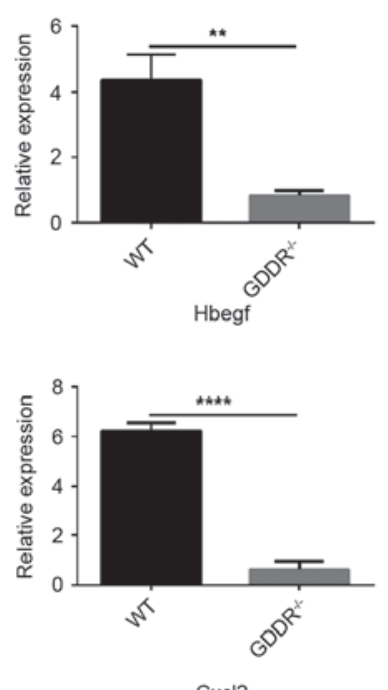

Cxcl2

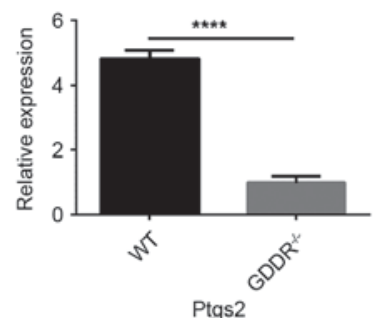

B
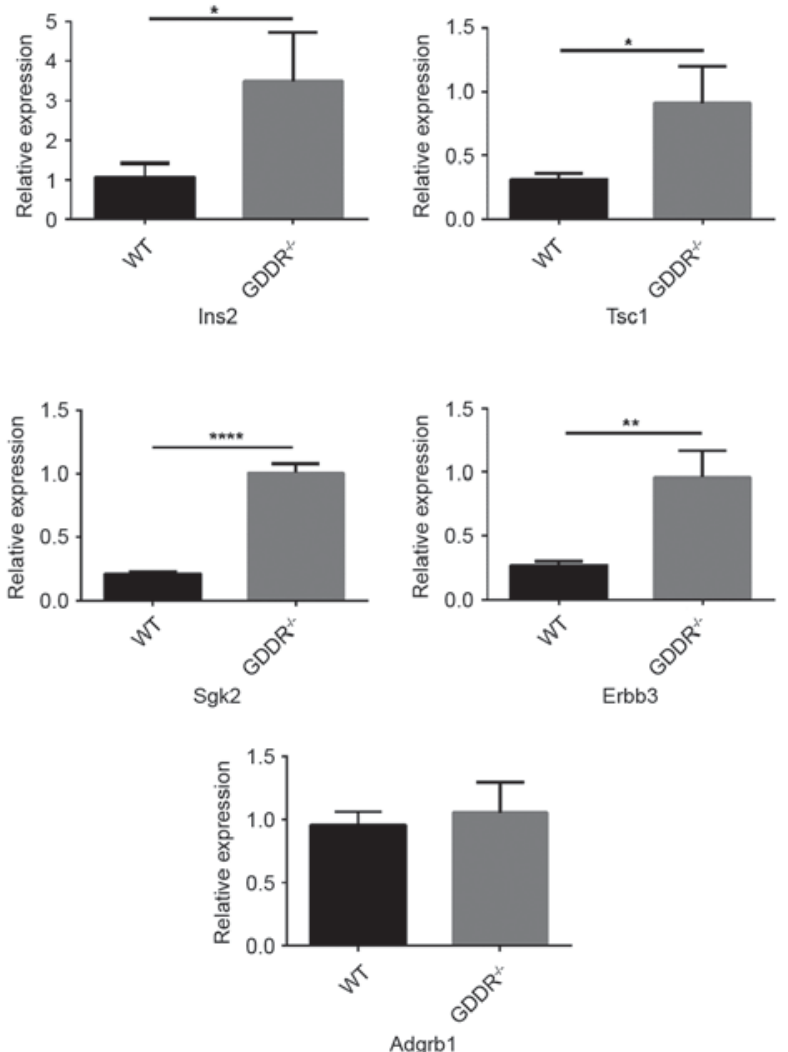
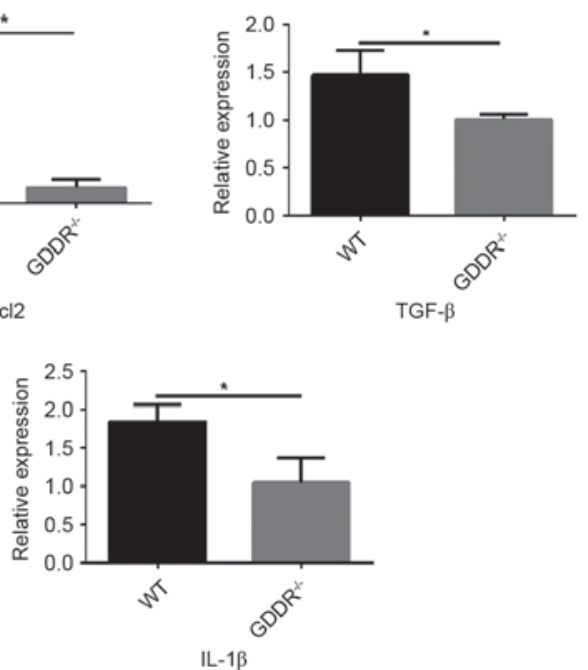

Figure 4. Reverse transcription-quantitative polymerase chain reaction analysis for validation of relative expression levels of representative differentiallyexpressed genes. (A) Upregulated genes in WT mice; (B) upregulated genes in knockout mice. ${ }^{*} \mathrm{P}<0.05,{ }^{* *} \mathrm{P}<0.01,{ }^{* * *} \mathrm{P}<0.001$, ${ }^{* * * * *} \mathrm{P}<0.0001$. WT, wild-type; GDDR, gastric dramatic downrelated gene; Hbegf, heparin binding EGF-like growth factor; Ptgs2, prostaglandin-endoperoxide synthase 2; Ins2, insulin II; Tsc1, tuberous sclerosis 1; Cxcl2, C-X-Cmotif chemokine ligand 2 ; Tgf- $\beta$, transforming growth factor- $\beta$; Sgk2, serine/threonine kinase 2 ; IL-1 $\beta$, interleukin; Adgrb, adhesion G protein-coupled receptor B1.

ligand-receptor interaction. The gastric lesion is the result of the disturbance between defensive and aggressive factors in the gastric mucosa (30), including mucus secretion, mucosal blood flow and repair processes. Previous studies have shown that the renin-angiotensin system is important in gastric mucosal protection (33). Evidence also indicates that the ECM-receptor interaction is involved during wound repair $(34,35)$. Activation in the PI3K-Akt signaling pathway has also been reported to be involved in protecting the gastric mucosal epithelium from damage (36). Therefore, investigation of these signaling pathways may assist in predictions of gastric lesions and wound repair.

In the present study, a PPI network was also constructed with the DEGs, and the top degree hub genes were identified, which were involved in phenotype: Per3, Ptgs2, Per2, Cry1, Per1, Actg2, Actc1, Nos2, Map3k1 and Gas7. Ptgs2, also known as cyclooxygenase 2 (Cox-2), serves as the key enzyme in the process of prostaglandin biosynthesis, and is a peroxidase and dioxygenase. Ptgs2 is involved in the production of inflammatory prostaglandins, and the upregulation of Ptgs 2 is involved in phenotypic changes, increased cell adhesion, resistance to apoptosis and tumor angiogenesis. Previous studies have reported that the expression of Cox-2 is induced in inflammatory cells at sites of inflammation (37), and the presence of Cox-2 in the intact gastric mucosa is crucial for protection against injury caused by non-steroidal anti-inflammatory agents (38). The second hub gene, Cryl, is a core component of the circadian clock, which regulates various physiological processes through gene expression according to circadian rhythms of $\sim 24 \mathrm{~h}$. It is an important regulator of a broad set of physiological functions, including immune and endocrine functions, which are involved in gastric lesions (39-41). The third hub gene, Perl, is a member of the period family of genes and functions in the repression of glucocorticoid receptor $\mathrm{Nr} 3 \mathrm{c} 1 / \mathrm{Gr}$-induced transcriptional activity. It is important in gastric mucosal defense $(42,43)$ by reducing the association between $\mathrm{Nr} 3 \mathrm{cl} / \mathrm{Gr}$ and glucocorticoid response elements. In addition, Per1 is involved in modulating the inflammatory state via regulating the release of inflammatory mediators, including Ccl2 and IL6. Per2 is also a member of the period family, and is involved in maintaining cardiovascular functions through the regulation of $\mathrm{NO}$ and vasodilatatory prostaglandin production. Cry1 and Cry2 are transported into the nucleus by Per1 and Per2 proteins, with appropriate circadian timing. Cry1 and cry 2 exhibit repressing activity, which has a direct effect on clock-controlled target genes by interacting with groups of RNA-binding proteins, helicases and other transcriptional repressors (44). There is increasing evidence indicating that the functional disturbance of Nos2 can affect the response to hypoxia (45) and innate immune response in the mucosa (46). It can release $\mathrm{NO}$, serving as a messenger molecule with distinct biological functions in the body. Map3k1 encodes 
a serine/threonine kinase and is known to be involved in certain signal-transduction cascades encompassing the c-Jun $\mathrm{N}$-terminal kinase and extracellular signal-regulated kinase kinase pathways, and the nuclear factor-kB pathway. Reactive oxygen species are signaling molecules, which function in stimulating the protein synthesis of hypoxia-inducible factor $1 \alpha($ Hif- $1 \alpha)$ through activating the mitogen-activated protein kinase (MAPK) pathways (47). To date, the biological functions of MAPK in acute gastric lesion remains to be elucidated.

Based on module analysis of the PPI networks, the process of gastric lesions in WT mice were associated with regulation of the glucocorticoid receptor signaling pathway, regulation of the cellular stress response to stress, and regulation of hormone secretion. It has been established that acutely increased corticosterone has a protective effect on the stomach against injury induced by stress (48). It has also been demonstrated that the gastroprotective activity of glucocorticoids results from the maintenance of mucus secretion, repair processes and gastric mucosal blood flow, and the attenuation of harmful factors, including increasing microvascular permeability and gastric motility $(47,49)$. In addition, glucocorticoids have a compensatory gastroprotective role if the gastro-protective mechanisms rendered by NO, capsaicin-sensitive sensory neurons and prostaglandins are impaired (48).

The present study focused on the differences caused by GDDR under stress-induced conditions. The WT and KOmice groups were used to compare and analyze the differences. The correlation between the expression of DEGs and the degree of pathologic damage was not examined in the present study and requires further investigation. The present study focused on examining the differences between WT mice and GDDR-/mice associated with phenotype. The DEGs analyzed in the present study were also based on phenotype. As, in the absence of stress, no significant differences are found between the WT mice and KO mice, the gene expression profiles in WT mice with and without stress were not examined in the present study.

In conclusion, comprehensive bioinformatics analysis of the DEGs was performed in the present study, which may be associated with acute gastric lesions and regulated by GDDR. The results provided an array of potent targets for future investigations of the molecular mechanisms. The functions of the genes identified in gastric lesions require confirmation in further molecular biological experiments.

\section{Acknowledgements}

This study was supported by the National Natural Science Foundation of China (grant no. 81270440).

\section{References}

1. Brodie DA and Hooke KF: The effect of vasoactive agents on stress-induced gastric hemorrhage in the rat. Digestion 4: 193-204, 1971.

2. Ernst H, Konturek PC, Brzozowski T, Lochs H, Hahn EG and Konturek SJ: Adaptation of gastric mucosa to stress. Effect of ranitidine. J Physiol Pharmacol 49: 405-419, 1998.

3. Guo S, Gao Q, Jiao Q, Hao W, Gao X and Cao JM: Gastric mucosal damage in water immersion stress: Mechanism and prevention with GHRP-6. World J Gastroenterol 18: 3145-3155, 2012.

4. Robles TF and Carroll JE: Restorative biological processes and health. Soc Personal Psychol Compass 5: 518-537, 2011.
5. Lin HP, Lin HY, Lin WL and Huang AC: Effects of stress, depression, and their interaction on heart rate, skin conductance, finger temperature, and respiratory rate: Sympathetic-parasympathetic hypothesis of stress and depression. J Clin Psychol 67: 1080-1091, 2011.

6. Du JJ, Dou KF, Peng SY, Wang WZ, Wang ZH, Xiao HS, Guan WX, Liu YB and Gao ZQ: Down-regulated full-length novel gene GDDR and its effect on gastric cancer. Zhonghua Yi Xue Za Zhi 83: 1166-1168, 2003 (In Chinese).

7. Du JJ, Dou KF, Peng SY, Li JT, Wang WZ, Guan WX and Gao ZQ: Study on novel gene GDDR related to gastric cancer. Zhonghua Wai Ke Za Zhi 43: 10-13, 2005 (In Chinese).

8. May FE, Griffin SM and Westley BR: The trefoil factor interacting protein TFIZ1 binds the trefoil protein TFF1 preferentially in normal gastric mucosal cells but the co-expression of these proteins is deregulated in gastric cancer. Int J Biochem Cell Biol 41: 632-640, 2009.

9. Baus-Loncar M, Lubka M, Pusch CM, Otto WR, Poulsom R and Blin N: Cytokine regulation of the trefoil factor family binding protein GKN2 (GDDR/TFIZ1/blottin) in human gastrointestinal epithelial cells. Cell Physiol Biochem 20: 193-204, 2007.

10. Menheniott TR, O'Connor L, Chionh YT, Däbritz J, Scurr M, Rollo BN, Ng GZ, Jacobs S, Catubig A, Kurklu B, et al: Loss of gastrokine-2 drives premalignant gastric inflammation and tumor progression. J Clin Invest 126: 1383-1400, 2016.

11. Moss SF, Lee JW, Sabo E, Rubin AK, Rommel J, Westley BR, May FE, Gao J, Meitner PA, Tavares R and Resnick MB: Decreased expression of gastrokine 1 and the trefoil factor interacting protein TFIZ1/GKN2 in gastric cancer: Influence of tumor histology and relationship to prognosis. Clin Cancer Res 14: 4161-4167, 2008.

12. Chu G, Qi S, Yang G, Dou K, Du J and Lu Z: Gastrointestinal tract specific gene GDDR inhibits the progression of gastric cancer in a TFF1 dependent manner. Mol Cell Biochem 359: 369-374, 2012.

13. Shi LS, Wang H, Wang F, Feng M, Wang $M$ and Guan WX: Effects of gastrokine2 expression on gastric cancer cell apoptosis by activation of extrinsic apoptotic pathways. Mol Med Rep 10: 2898-2904, 2014

14. Kim O, Yoon JH, Choi WS, Ashktorab H, Smoot DT, Nam SW, Lee JY and Park WS: GKN2 contributes to the homeostasis of gastric mucosa by inhibiting GKN1 activity. J Cell Physiol 229: 762-771, 2014

15. Menheniott TR, Kurklu B and Giraud AS: Gastrokines: Stomach-specific proteins with putative homeostatic and tumor suppressor roles. Am J Physiol Gastrointest Liver Physiol 304: G109-G121, 2013.

16. Gang W, Chen F, Xiangui L, et al: The role of new gene GDDR in the acute and chronic gastric mucosal injury in mice. Progress in Modern Biomedicine 10: 1836-1839, 2015.

17. Shimozawa N, Okajima K, Harada N, Arai M, Ishida Y, Shimada S, Kurihara H and Nakagata N: Contribution of sensory neurons to sex difference in the development of stress-induced gastric mucosal injury in mice. Gastroenterology 131: 1826-1834, 2006.

18. Menheniott TR, Peterson AJ, O'Connor L, Lee KS, Kalantzis A, Kondova I, Bontrop RE, Bell KM and Giraud AS: A novel gastrokine, Gkn3, marks gastric atrophy and shows evidence of adaptive gene loss in humans. Gastroenterology 138: 1823-1835, 2010.

19. Santucci L, Fiorucci S, Giansanti M, Brunori PM, Di Matteo FM and Morelli A: Pentoxifylline prevents indomethacin induced acute gastric mucosal damage in rats: Role of tumour necrosis factor alpha. Gut 35: 909-915, 1994.

20. Trapnell C, Pachter L and Salzberg SL: TopHat: Discovering splice junctions with RNA-Seq. Bioinformatics 25: 1105-1111, 2009.

21. Gene Ontology C: The Gene Ontology (GO) project in 2006. Nucleic Acids Research 34: D322-326, 2006.

22. Kanehisa M and Goto S: KEGG: Kyoto encyclopedia of genes and genomes. Nucleic Acids Res 28: 27-30, 2000.

23. Dennis G Jr., Sherman BT, Hosack DA, Yang J, Gao W, Lane HC and Lempicki RA: DAVID: Database for annotation, visualization, and integrated discovery. Genome Biol 4: P3, 2003.

24. Barabási AL and Oltvai ZN: Network biology: Understanding the cell's functional organization. Nat Rev Genet 5: 101-113, 2004.

25. Prieto C, Risueño A, Fontanillo C and De las Rivas J: Human gene coexpression landscape: Confident network derived from tissue transcriptomic profiles. PLoS One 3: e3911, 2008. 
26. Livak KJ and Schmittgen TD: Analysis of relative gene expression data using real-time quantitative PCR and the 2(-Delta Delta C(T)) method. Methods 25: 402-408, 2001.

27. Wang L, Wang S and Li W: RSeQC: Quality control of RNA-seq experiments. Bioinformatics 28: 2184-2185, 2012.

28. Nishida K, Ohta Y and Ishiguro I: Changes in nitric oxide production with lesion development in the gastric mucosa of rats with water immersion restraint stress. Res Commun Mol Pathol Pharmacol 100: 201-212, 1998.

29. S Kwiecien S, Pawlik MW, Brzozowski T, Konturek PC, Sliwowski Z, Pawlik WW and Konturek SJ: Nitric oxide (NO)-releasing aspirin and (NO) donors in protection of gastric mucosa against stress. J Physiol Pharmacol 59 (Suppl 2): S103-S115, 2008.

30. Brzozowska I, Ptak-Belowska A, Pawlik M, Pajdo R, Drozdowicz D, Konturek SJ, Pawlik WW and Brzozowski T: Mucosal strengthening activity of central and peripheral melatonin in the mechanism of gastric defense. J Physiol Pharmacol 60 (Suppl 7): 47-56, 2009.

31. Nur Azlina MF, Kamisah Y, Chua KH and Qodriyah HM: Tocotrienol attenuates stress-induced gastric lesions via activation of prostaglandin and upregulation of COX-1 mRNA. Evid Based Complement Alternat Med 2013: 804796, 2013.

32. Li YM, Lu GM, Zou XP, Li ZS, Peng GY and Fang DC: Dynamic functional and ultrastructural changes of gastric parietal cells induced by water immersion-restraint stress in rats. World J Gastroenterol 12: 3368-3372, 2006.

33. Brzozowski T: Role of renin-angiotensin system and metabolites of angiotensin in the mechanism of gastric mucosal protection. Curr Opin Pharmacol 19: 90-98, 2014.

34. Rohani MG and Parks WC: Matrix remodeling by MMPs during wound repair. Matrix Biol 44-46: 113-121, 2015.

35. Wilgus TA: Growth factor-extracellular matrix interactions regulate wound repair. Adv Wound Care (New Rochelle) 1: 249-254, 2012.

36. Sun Z, Liu H, Yang Z, Shao D, Zhang W, Ren Y, Sun B, Lin J, $\mathrm{Xu} \mathrm{M}$ and Nie S: Intestinal trefoil factor activates the PI3K/Akt signaling pathway to protect gastric mucosal epithelium from damage. Int J Oncol 45: 1123-1132, 2014

37. Seibert K, Zhang Y, Leahy K, Hauser S, Masferrer J, Perkins W, Lee $\mathrm{L}$ and Isakson P: Pharmacological and biochemical demonstration of the role of cyclooxygenase 2 in inflammation and pain Proc Natl Acad Sci USA 91: 12013-12017, 1994.

38. Wallace JL, McKnight W, Reuter BK and Vergnolle N NSAID-induced gastric damage in rats: Requirement for inhibition of both cyclooxygenase 1 and 2. Gastroenterology 119: 706-714, 2000
39. Baek YH, Lee KN, Jun DW, Yoon BC, Kim JM, Oh TY and Lee OY: Augmenting effect of DA-9601 on ghrelin in an acute gastric injury model. Gut Liver 5: 52-56, 2011.

40. Adami M, Pozzoli C, Leurs R, Stark H and Coruzzi G: Histamine $\mathrm{H}(3)$ receptors are involved in the protective effect of ghrelin against $\mathrm{HCl}$-induced gastric damage in rats. Pharmacology 86: 259-266, 2010.

41. Okajima K, Murakami K, Liu W and Uchiba M: Inhibition of neutrophil activation by ranitidine contributes to prevent stress-induced gastric mucosal injury in rats. Crit Care Med 28: 2858-2865, 2000

42. Mifsud KR and Reul JM: Acute stress enhances heterodimerization and binding of corticosteroid receptors at glucocorticoid target genes in the hippocampus. Proc Natl Acad Sci USA 113: 11336-11341, 2016

43. Filaretova LP, Filaretov AA and Makara GB: Corticosterone increase inhibits stress-induced gastric erosions in rats. Am J Physiol 274: G1024-G1030, 1998.

44. Lee Y, Jang AR, Francey LJ, Sehgal A and Hogenesch JB KPNB1 mediates PER/CRY nuclear translocation and circadian clock function. ELife 4, 2015.

45. Zhang F, Wu W, Deng Z, Zheng X, Zhang J, Deng S, Chen J, Ma Q, Wang Y, Yu X, et al: High altitude increases the expression of hypoxia-inducible factor lalpha and inducible nitric oxide synthase with intest-inal mucosal barrier failure in rats. Int J Clin Exp Pathol 8: 5189-5195, 2015.

46. Bogdan C: Nitric oxide synthase in innate and adaptive immunity: An update. Trends Immunol 36: 161-178, 2015.

47. Wang $T$, Leng $Y F$, Zhang $Y$, Xue $X$, Kang YQ and Zhang Y: Oxidative stress and hypoxia-induced factor $1 \alpha$ expression in gastric ischemia. World J Gastroenterol 17: 1915-1922, 2011.

48. Filaretova L: Glucocorticoids are gastroprotective under physiologic conditions. Ther Adv Chronic Dis 2: 333-342, 2011.

49. Filaretova LP, Podvigina TT, Bagaeva TR, Tanaka A and Takeuchi K: Mechanisms underlying the gastroprotective action of glucocorticoids released in response to ulcerogenic stress factors. Ann N Y Acad Sci 1018: 288-292, 2004. 